\title{
Thyroid eye disease
}

\author{
Michel J. Belliveau MD, David R. Jordan MD
}

\section{Thyroid eye disease can occur with- out hyperthyroidism}

About $90 \%$ of patients with thyroid eye disease have Graves hyperthyroidism, but hypothyroidism and euthyroidism can also accompany this condition. ${ }^{1}$ Eye disease usually develops in patients with hyperthyroidism within the first 12 years, but the disease can occur decades later.

\section{Thyroid eye disease can lead to blindness}

Most patients receive conservative treatment - lubrication of the eye to reduce symptoms related to disturbance of the tear film. About $5 \%$ of patients will need more aggressive therapy (e.g., systemic corticosteroids, orbital radiation, surgical removal of orbital walls) to prevent vision loss caused by either compression of the optic nerve by enlarging extraocular muscles or corneal ulceration due to exposure. ${ }^{2}$ Red flags for urgent consultation with an ophthalmologist include reduction in visual acuity or colour vision, relative afferent pupillary defect, swelling of the optic disc, corneal opacity and severe periorbital swelling.

\section{References}

1. Bartley GB, Fatourechi V, Kadrmas EF, et al Clinical features of Graves' ophthalmopathy in an incidence cohort. Am J Ophthalmol 1996;121: 284-90.

2. Rootman J, Dolman PJ. Thyroid orbitopathy. In: Rootman J, editor. Disease of the orbit: a multidisciplinary approach. 2nd ed. Philadelphia (PA): Lippincott Williams \& Wilkins; 2003. p. 169-212.

\section{Hallmark features of the disease include retraction of the eyelid, exophthalmos and restricted ocu- lar movement}

Retraction of the eyelid (Figure 1) is the most common clinical sign, present in $90 \%$ of patients with thyroid eye disease. Exophthal$\operatorname{mos}(60 \%$ of patients) and restricted eye movement ( $40 \%$ of patients) are also common. ${ }^{1}$

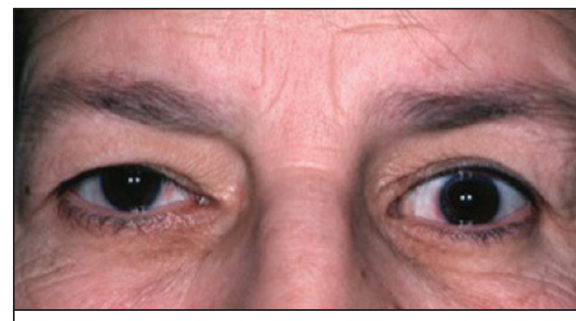

Figure 1: Photograph showing retraction of the left upper eyelid. The upper eyelid normally rests just below the limbus, the lower eyelid at the limbus.

\section{Removal of the thyroid does not cure thyroid eye disease}

Thyroid eye disease is driven by autoantigens on orbital fibroblasts that are also expressed by thyroid epithelium. ${ }^{3}$ The eye disease and systemic disease often have distinct clinical courses. Although supporting evidence is limited, achieving euthyroidism with the assistance of an endocrinologist is recommended, particularly in moderate to severe cases. ${ }^{4}$ Steroid prophylaxis can prevent the eye disease from worsening after thyroid ablation with radioactive iodine. ${ }^{4}$ Thyroid removal has little or no additional effect on the natural history of thyroid eye disease.

3. Bahn RS. Graves ophthalmopathy. $N$ Engl J Med 2010;362:726-38.

4. Hegedüs L, Bonnema SJ, Smith TJ, et al. Treating the thyroid in the presence of Graves' ophthalmopathy. Best Pract Res Clin Endocrinol Metab 2012;26: 313-24.

5. Thornton J, Kelly SP, Harrison RA, et al. Cigarette smoking and thyroid eye disease: a systematic review. Eye (Lond) 2007;21:1135-45
Smoking is associated with the development, progression and poor response to treatment of thyroid eye disease

Smoking increases the risk of thyroid eye disease (odds ratio 1.910.1), and disease progression and poor treatment outcomes are more likely to occur in people who smoke. Thus, smoking cessation is the most important modifiable risk factor. ${ }^{5}$

Competing interests: None declared.

This article has been peer reviewed.

Affiliations: From the Department of Ophthalmology (Belliveau), Queen's University, Kingston, Ont.; and the Department of Ophthalmology (Jordan), University of Ottawa Eye Institute, and The Ottawa Hospital, Ottawa, Ont.

Correspondence to: David R. Jordan, jordan 1897 @ rogers.com

CMAJ 2013. DOI:10.1503/cmaj.121815 